\title{
Prediction and Evaluation of Waterjet Pump Performance under Nonuniform Inflow Using Parallel Compressor Theory
}

\author{
Puyu Cao ${ }^{1}$ and Rui Zhu ${ }^{2, *}$ \\ 1 National Research Center of Pumps, Jiangsu University, Zhenjiang 212013, China; mafatu1988@ujs.edu.cn \\ 2 School of Energy and Power Engineering, Xi'an Jiaotong University, Xi'an 71049, China \\ * Correspondence: ruizhu@stu.xjtu.edu.cn
}

check for updates

Citation: Cao, P.; Zhu, R. Prediction and Evaluation of Waterjet Pump Performance under Nonuniform Inflow Using Parallel Compressor Theory. Water 2021, 13, 99. https://doi.org/10.3390/w13010099

Received: 19 November 2020 Accepted: 29 December 2020 Published: 4 January 2021

Publisher's Note: MDPI stays neutral with regard to jurisdictional clai$\mathrm{ms}$ in published maps and institutional affiliations.

Copyright: (C) 2021 by the authors. Licensee MDPI, Basel, Switzerland. This article is an open access article distributed under the terms and conditions of the Creative Commons Attribution (CC BY) license (https:// creativecommons.org/licenses/by/ $4.0 /)$.

\begin{abstract}
Parallel compressor theory (PCT) is commonly used to estimate effects of inlet distortion on compressor performance. As well as compressor, the actual inflow to pump is also nonuniform and unfavorable for performances. Nowadays, insufficient understanding of nonuniform inflow effects on pump performance restricts its development. Therefore, this paper applies PCT to predict external characteristics and evaluate internal flow instability of waterjet pump under nonuniform inflow. According to features of nonuniform inflow, the traditional PCT is modified and makes waterjet pump sub-divided into two circumferential tubes owning same performances but with different inlet velocity (representing nonuniform inflow). Above all, numerical simulation has been conducted to validated the applicability and accuracy of PCT in head prediction of waterjet pump under nonuniform inflow, since area-weighted sum of each tube head (i.e., theoretical pump head) is highly consistent with simulated result. Moreover, based on identifications of when and which tube occurs stall, PCT evaluates four stall behaviors of waterjet pump: partial deep stall, partial stall, pre-stall and full stall. Furthermore, different stall behavior generates different interactions between head variation of each tube, resulting in a multi-segment head curve under nonuniform inflow. The modified PCT with associated physical interpretations are expected to provide a sufficient understanding of nonuniform inflow effects on pump performances.
\end{abstract}

Keywords: waterjet pump; nonuniform inflow; parallel compressor theory; stall; head

\section{Introduction}

Waterjet pump delivers power to working fluid and generates high speed jet to drive surface and underwater vessels [1]. In recent years, waterjet pump gradually replaces the tradition propeller application in high speed or high stable vessels, such as river boat, motor boat, destroyer, submarine, torpedo, AUV (Autonomous underwater vehicle) and UUV (Unmanned underwater vehicle). With development of marine transportation and deep sea exploration, increasing demand has been put forward to high performances of waterjet pump, especially head and stability. However, satisfactory performances of waterjet pump in the test is hardly satisfied to the actual application, namely weaken performances at the actual operation is a challenge to waterjet pump. This is due to the fact that waterjet pump positioned closely to an intake duct at the actual operation, encounters with noticeable nonuniform inflow which is different from uniform inflow in the test [2]. In particular, insufficient understanding of weaken performances and nonuniform flow is a major problem encountered in the design and application of waterjet pumps. In essence, this paper aims to give a physical explanation of unfavorable effects of nonuniform inflow on performances of waterjet pump.

As for the nonuniform inflow to the waterjet pump, many researchers try to identify the origination and structure of non-uniform inflow by numerical or experimental methods [2-5]. But, effects of nonuniform inflow on performances of waterjet pump is barely addresses in literature [2,6]. On the contrary, the influence of inlet distortion (i.e., nonuni- 
form inflow) on external characteristics and internal flow stability of compressor has been investigated from the 1960s.

Many theory models have been established to predict and evaluate compressor performances, which could be used for reference in waterjet pump. The initial mean line code (MLC) [7,8] and streamline curvature code (SLCC) [9] which were designed based on the one-dimensional theory could predict the external characteristics of cascade and single stage compressor under inlet distortion with low accuracy. The nonlinear model developed by Greitzer [10] could give adequate predictions of compressor response for the rotating stall and surge transients at the stall limit line and he also provided the basic arguments about physical mechanism. The parallel compressor theory (PLC) [11-13] enriches the one-dimensional theory and lays a foundation for the analysis of the aerodynamic characteristics of compressors under circumferential distorted inflow. The dynamic turbine engine compressor code (DYNTECC) [14] derived from PCT is still used in the design and test of aero-compressor by Arnold Engineering Development Center [15,16].

The parallel compressor theory is the fundamental theory for the above models, and commonly used to investigate inlet distortion in aerodynamic turbomachinery. The parallel compressor theory is detail illustrated in Figure 1. The compressor which operates under inlet distortion is transformed into a compression parallel system with multiple inlets and a single exit. Several segments or tubes which are actually decomposed along the circumferential direction according to the total pressure distortion from the original compressor are contained in the parallel system. The influence of inlet distortion on the aerodynamic performance of the original compressor is determined by analyzing operations of each tube in the system. The idea of converting compressor into a parallel compressor system model is also worthy of predicting performances of waterjet pump in this paper.
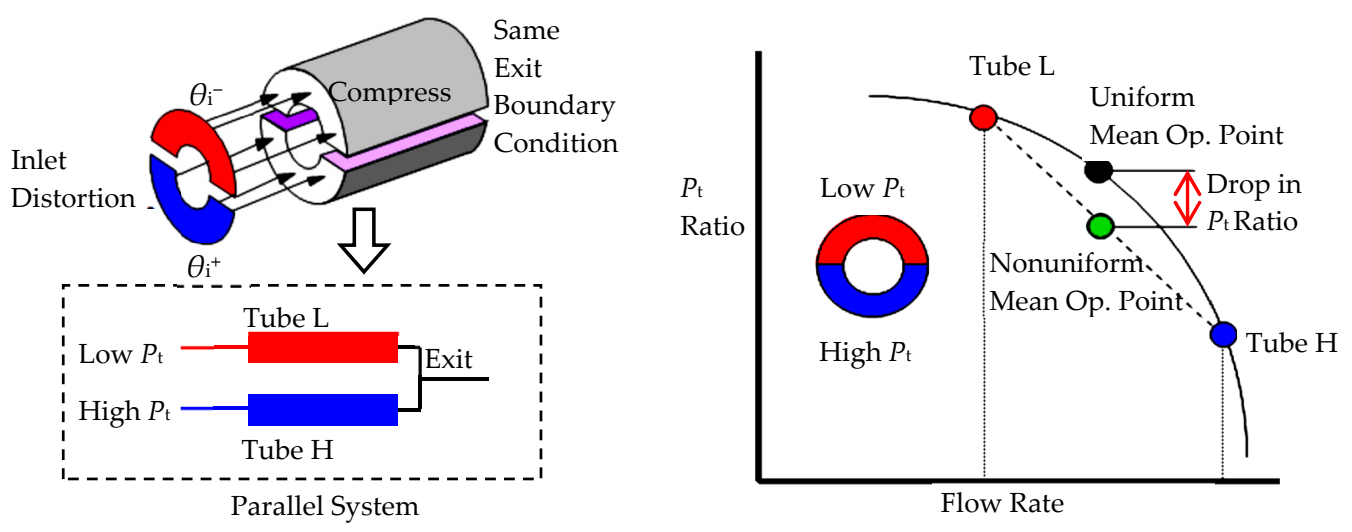

Figure 1. Parallel compressor theory concept [17].

In detail, compressor inlet section is divided into a high total pressure zone and a low total pressure zone as shown in Figure 1. The tube $\mathrm{H}$ corresponding to the high total pressure sector and the tube L corresponding to the low total pressure sector operate under various flow rates respectively (representing nonuniform inflow). It is assumed that tube $\mathrm{L}$ and tube $\mathrm{H}$ have the same compressor external characteristic curve obtained with uniform inflow. Accordingly, operating point of each tube can be projected to the same external characteristic curve. The weighted sum of the inlet total pressure of each tube is approximately equal to the circumferential total pressure of the original compressor. It is rather interesting to note that the weighted sum of flow rate of each tube is approximated to the operation flow of the original compressor; the weighted sum of pressure ratio of each tube is approximated to the pressure ratio of the original compressor under circumferential distorted inflow; the weight is equal to the value of dividing circumferential distortion range $\theta_{\mathrm{i}}$ of each tube by $360^{\circ}$ [17]. Therefore, the parallel system operating point corresponding waterjet pump under nonuniform inflow locates on the line connecting tube $\mathrm{L}$ 
and tube H. As plotted in Figure 1, the connecting line is obviously lower than the external characteristic curve with uniform inflow, which indicates that the pressure ratio weakens and reduces under the circumferential total pressure distortion.

Above all, the objective of this paper is twofold: first is to validate the applicability of parallel compressor theory in predicting external characteristics and evaluating the internal flow instability of waterjet pump under nonuniform inflow; second is to give a sufficient understanding of effects of nonuniform inflow on the stall behavior and its associated multi-segment head curve.

The remainder of the paper is organized as follows. Section 2 describes the numerical simulation method. The modified parallel compressor for waterjet pump under nonuniform inflow and the theoretical predict method are outlined in Section 3. In Section 4, the prediction of head and evaluation of stall behavior of waterjet pump based on parallel compressor theory are depicted successively. Section 5 discusses the correlation between stall behavior and multi-segment head curve. Conclusions are drawn in Section 6.

\section{Numerical Setup}

In the recent years, many studies have demonstrated that numerical simulations can accurately predict performances of the waterjet pump and its completely system [18,19]. Therefore, the commercial software ANSYS-CFX is used in this paper to simulate the three-dimensional flow within a waterjet pump under nonuniform inflow. Meanwhile, the steady simulation is also performed to obtain performances of a waterjet pump under the uniform inflow.

\subsection{Geometry of Waterjet Pump}

In this paper, the waterjet pump from propulsion system is driven by a diesel engine and installed in an inland vessel. The ship speed ranges from 21 to 42 knots. Based on design ship speed (30 knots) and the resistance curve, performance parameters of the corresponding waterjet pump were calculated: flow rate $Q_{\mathrm{d}}=3000 \mathrm{~m}^{3} / \mathrm{h}$, head $H_{\mathrm{d}}=8.8 \mathrm{~m}$, rotor speed $n_{\mathrm{d}}=1450 \mathrm{r} / \mathrm{min}$. Assuming the uniform suction flow, an axial-flow pump was designed to satisfy the requirements. Table 1 provides the geometric details of the water-jet pump.

Table 1. Main geometric parameters of an axial waterjet pump.

$\begin{array}{cc}\text { Number of impeller blades }\left[z_{\mathrm{R}}\right] & 3 \\ \text { Number of guide vanes }\left[z_{\mathrm{S}}\right] & 7 \\ \text { Impeller diameter }\left[D_{2}\right] & 447 \mathrm{~mm} \\ \text { Casing diameter }\left[D_{3}\right] & 450 \mathrm{~mm} \\ \text { Tip clearance }(\text { normal) } & 1.5 \mathrm{~mm} \\ \text { Hub ratio }\left[D_{\mathrm{h}} / D_{2}\right] & 0.4 \\ \text { Discharge nozzle diameter }\left[D_{\mathrm{j}}\right] & 250 \mathrm{~mm}\end{array}$

\subsection{Configuration, Grid and Boundary Conditions of Waterjet Pump under Nonuniform Inflow}

Figure 2 illustrates a 3D configuration of the waterjet pump under nonuniform inflow. The computation zone includes 5 individual parts to calculate pump performance under non-uniform inflow, namely, the impeller (rotor), guide vane (stator), discharge nozzle, intake duct and an upstream region. The upstream region represents the fluid domain below the hull and its reasonable size is $30 D_{2} \times 10 D_{2} \times 8 D_{2}$ [20], where $D_{2}$ is the impeller diameter.

CFX was used to simulate the complicate flow in the waterjet pump. The steady-state turbulent flow based on the Reynolds-averaged Navier-Stokes equations was solved by the RNG $k-\varepsilon$ model to give accurate predictions of the flow separation phenomena; and the scalable wall-function was used for the wall treatment. The accuracy of RNG $k-\varepsilon$ model has been validated in many reported articles [2,6]. During the steady calculation, the high-resolution scheme was used for the convection terms while the central difference 
scheme used for the diffusion terms. The fluid was the ideal water at $25^{\circ} \mathrm{C}$. The convergence precision was based on reducing the maximum of the normalized residuals of the momentum and continuity equations to less than $10^{-5}$.

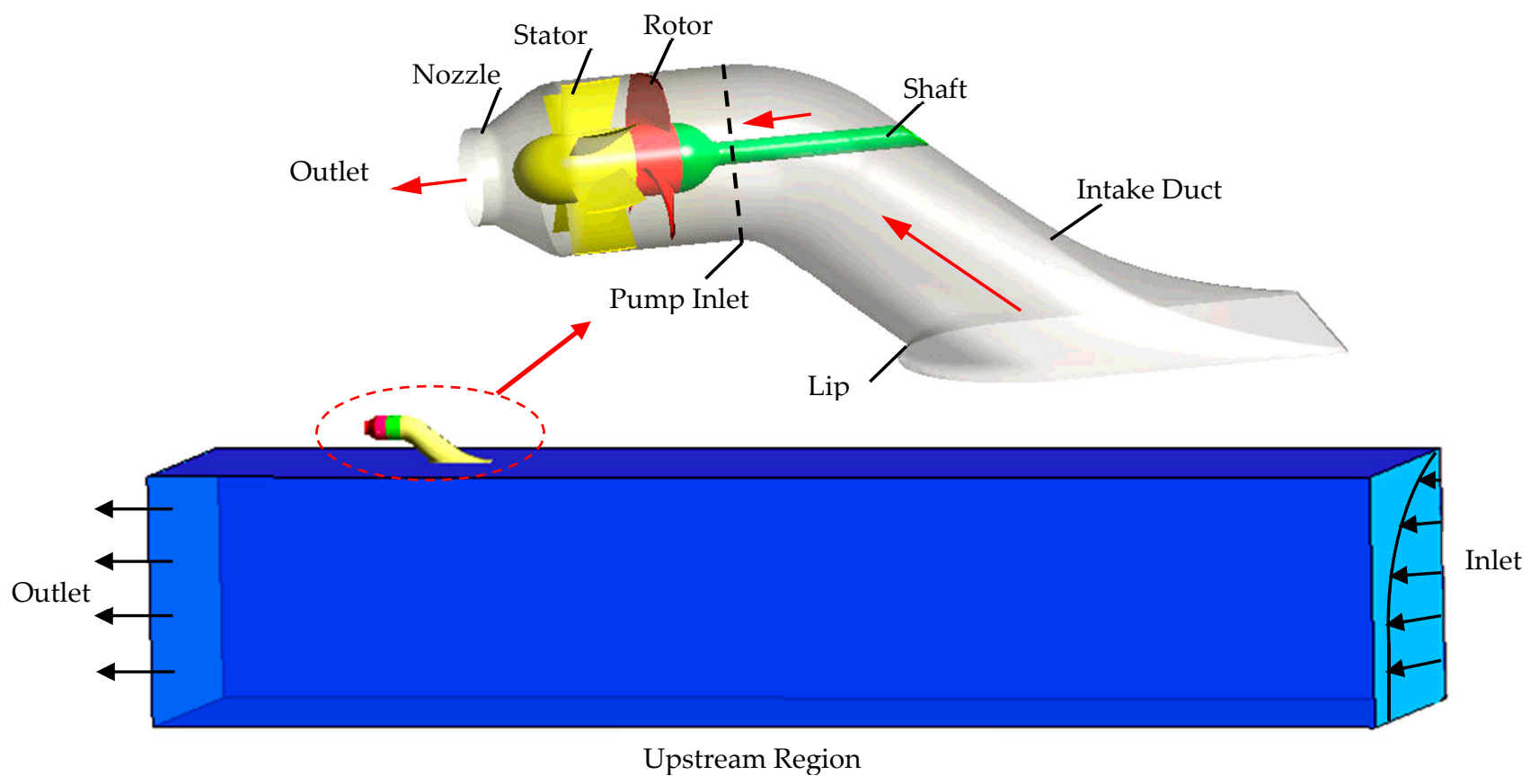

Figure 2. Configuration of a waterjet pump under nonuniform suction.

Structured hexahedral mesh is generated for the whole computational domain using ANSYS-ICEM mesh generation tool, which has a small truncation error and better convergence characteristic during numerical simulation. As described in Figure 3, the impeller and guide vane were discretized by H-type blocks. Meanwhile, both the discharge nozzle and intake duct were discretized by O-type blocks. Grid refinement was set up on the solid walls, especially the blade surfaces and the interface between the duct and upstream region. Thus, the boundary-layer was reasonably controlled, and the $y^{+}$on solid surfaces was in a proper range. CFD calculations at the design point were repeated on four grids with increasing size to perform grid independency analysis on the whole domain, the pump head calculated with four grids were normalized with respect to $H_{\text {Grid } 4}$ and plotted in Figure 4 . Grid 3 presented less than $0.5 \%$ variation of the normalized head, thus it was eventually selected for this study. The total node number of Grid 3 is about 4.3 million. In detail, the number of the impeller is $128 \times 74 \times 86$ (axial, spanwise, pitch), and it is $150 \times 72 \times 75$ for the guide vane. The grid quality is about 0.6 and the average $y^{+}$is around 40 , which is suitable for the scalable wall-function.'

CFX was used to simulate the complicate flow in the waterjet pump. The steady-state turbulent flow based on the Reynolds-averaged Navier-Stokes equations was solved by the RNG $k-\varepsilon$ model to give accurate predictions of the flow separation phenomena; and the scalable wall-function was used for the wall treatment. The accuracy of RNG $k-\varepsilon$ model has been validated in many reported articles [2,6]. During the steady calculation, the high resolution scheme was used for the convection terms while the central difference scheme used for the diffusion terms. The fluid was the ideal water at $25^{\circ} \mathrm{C}$. The convergence precision was based on reducing the maximum of the normalized residuals of the momentum and continuity equations to less than $10^{-5}$. 


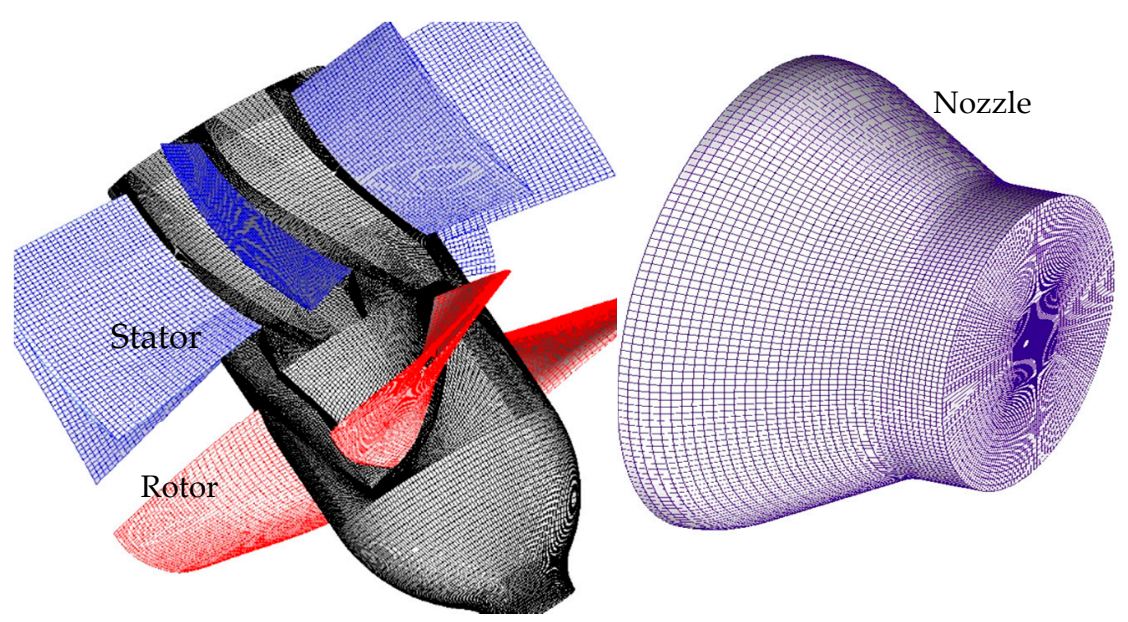

(a) Rotor and Stator

(b) Nozzle

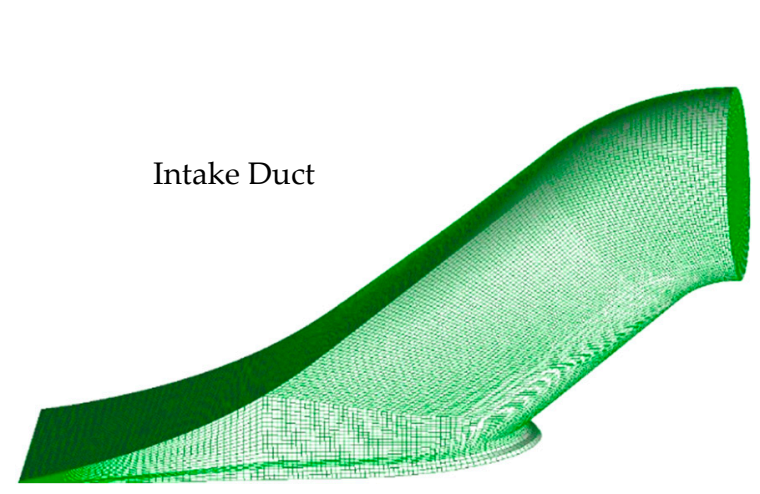

(c) Intake Duct

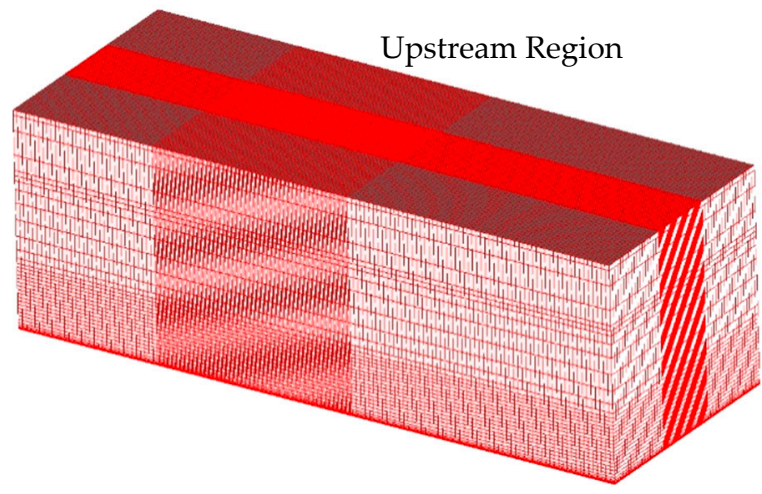

(d) Upstream region

Figure 3. 3D view of multi-block grid in the waterjet pump.

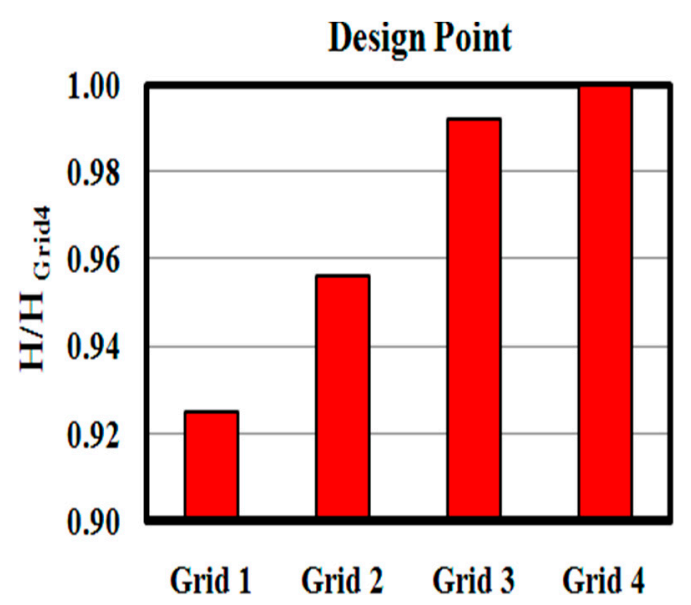

(a)

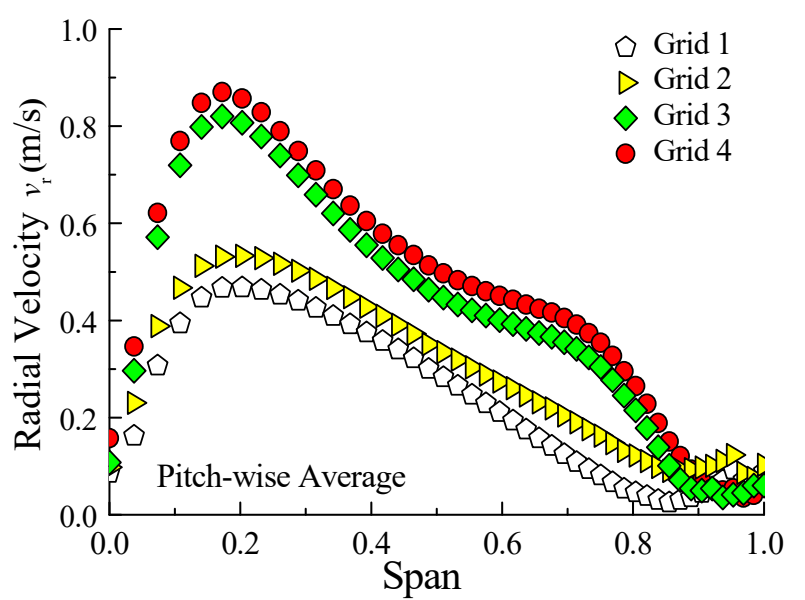

(b)

Figure 4. Grid independency analysis-(a) Normalized pump head at design point; (b) Pitch-averaged, spanwise distribution of the radial velocity at the impeller blade leading edge, at design point.

As seen in the vessel frame of reference, the upstream region was set as a stationary frame, but the side and lower walls of the domain below the hull were set as relative motion (30 knots). The trim angle of the hull was fixed at 0 (even keel). The intake duct domain was also set as a stationary frame, in which the penetrating shaft was set as relative rotation 
(1450 $\mathrm{r} / \mathrm{min})$. The impeller domain was set as the rotating frame with design shaft speed $(1450 \mathrm{r} / \mathrm{min})$. The guide vane and nozzle were set as a stationary frame. Furthermore, the interface between the stationary frame and the rotating frame was set as the rotor-stator interface, where frozen rotor method was used for the frame change. Moreover, all the physical walls were set as nonslip walls.

The outlet boundary condition of the nozzle was set as opening, and the outlet boundary condition of the upstream region was set as an average static pressure condition. The inlet boundary condition was set as a velocity normal to the inlet, and the initial velocity distribution was determined by Equation (1). The actual inlet velocity was related to the ship speed, and considered the velocity gradient by the boundary layer below the hull. The boundary layer thickness was calculated by Wieghardt equation $[2,20]$.

$$
\begin{gathered}
\text { Actual inlet velocity } v_{\text {in }}=\left\{\begin{array}{c}
v_{s}\left(\frac{y}{\delta}\right)^{\frac{1}{N}}, y \leq \delta \\
v_{s}, y>\delta
\end{array}\right\} \\
\text { Boundary layer thickness } \delta=0.27 x_{\mathrm{w}}(R e)^{-1 / 6}
\end{gathered}
$$

where $v_{s}$ is the ship speed, $y$ is the depth normal to hull bottom, the power law exponent $N=9$ is used, $R e$ is the Reynolds number in relation to the wetted length $x_{\mathrm{w}}$.

By changing ship speed, the steady-state simulations of the waterjet pump under nonuniform inflow were carried out, and then hydraulic performances were obtained. As shown in Figure 2, the flow rate was calculated at the outlet of the nozzle and the nonuniform flow detail was calculated at the pump inlet section, which was the interface between the intake duct and the pump. Moreover, the pump head was calculated on the basis of the total pressure difference between the nozzle outlet and the pump inlet section. This simulated head contained hydraulic losses in the nozzle with no losses in the intake duct.

\subsection{Configuration, Grid and Boundary Conditions of Waterjet Pump under Uniform Inflow}

The computation zone of waterjet pump under nonuniform inflow was divided into 4 parts. Compared with the waterjet pump under nonuniform inflow, the nozzle, guide vane diffuser and impeller were unchanged. However, intake duct and upstream region were replaced by a straight pipe, whose length is $2.5 D_{2}$ to keep the pump inflow uniform under conditions.

The same multi-block grids of the waterjet pump were used in this steady simulation. Meanwhile, most numerical settings were remained, and the major change occurred in the boundary conditions. The average total pressure was imposed as an inlet boundary condition of the waterjet pump under uniform inflow, and the outlet boundary condition was set as the mass flow rate in accordance with the numerical result of the nonuniform inflow model. By changing the mass flow rate, pump performances under the uniform inflow were achieved. In detail, the pump head was calculated between the same sections.

\subsection{Simulation Model Validation}

In order to validate the accuracy of the current numerical method, the waterjet pump under the uniform inflow has been examined in a closed test loop facility, where the experimental uncertainty errors of the head and flow rate are all below $0.5 \%$.

Figure 5 compares the experimental curve of $Q-H$ with the numerical data under the uniform suction flow. As a result, the predicted head tendency at flow rate $Q / Q_{d}=0.85-1.1$ presents a desirable agreement with the experimental curve. At the design flow rate, the prediction error is below $1 \%$. The maximum error is $2.76 \%$ at a large flow rate, due to an increase in the leakage flow rate. Hence, the simulation model is suitable for the following analysis. 


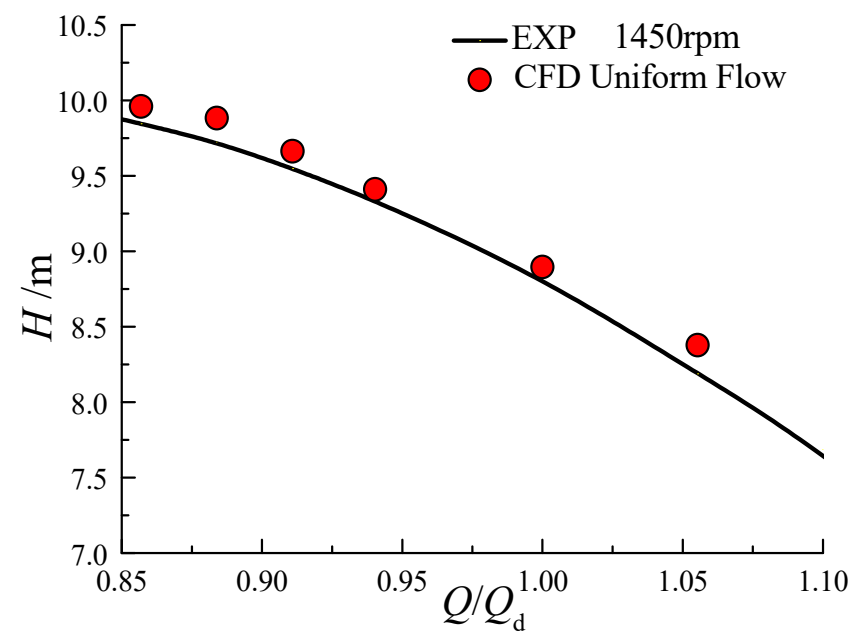

Figure 5. Head comparison between experimental and numerical results, at $1450 \mathrm{r} / \mathrm{min}$.

\section{A modified Parallel Compressor Theory to Waterjet Pump under Nonuniform Inflow}

According to flow features of the nonuniform inflow, the traditional parallel compressor theory should be modified to predict and evaluate the distorted performance of waterjet pump.

Previous research has verified that the primary feature of nonuniform inflow is a circumferential vortex fixed on the top of pump inlet surface [21]. As shown in Figure 6, the distorted flow field upstream of the pump is characterized by two regions: one is the top region associated with the vortex is defined as the distorted sector ranging from $-60^{\circ}$ to $60^{\circ}$; the other region is defined as the clean sector. According to the circumferential range of distorted and clean sectors, the overall control volume of waterjet pump is divided into two circumferential and parallel tubes that extend from distorted/clean sector downstream to the exit. In detail, tube L, colored by red in Figure 6, corresponds to the distorted sector and mainly operates at low flow rate; tube $\mathrm{H}$, colored by blue in Figure 6, corresponds to the clean sector and almost operates at high flow rate. Therefore, the waterjet pump under nonuniform inflow is converted into a parallel pump system.
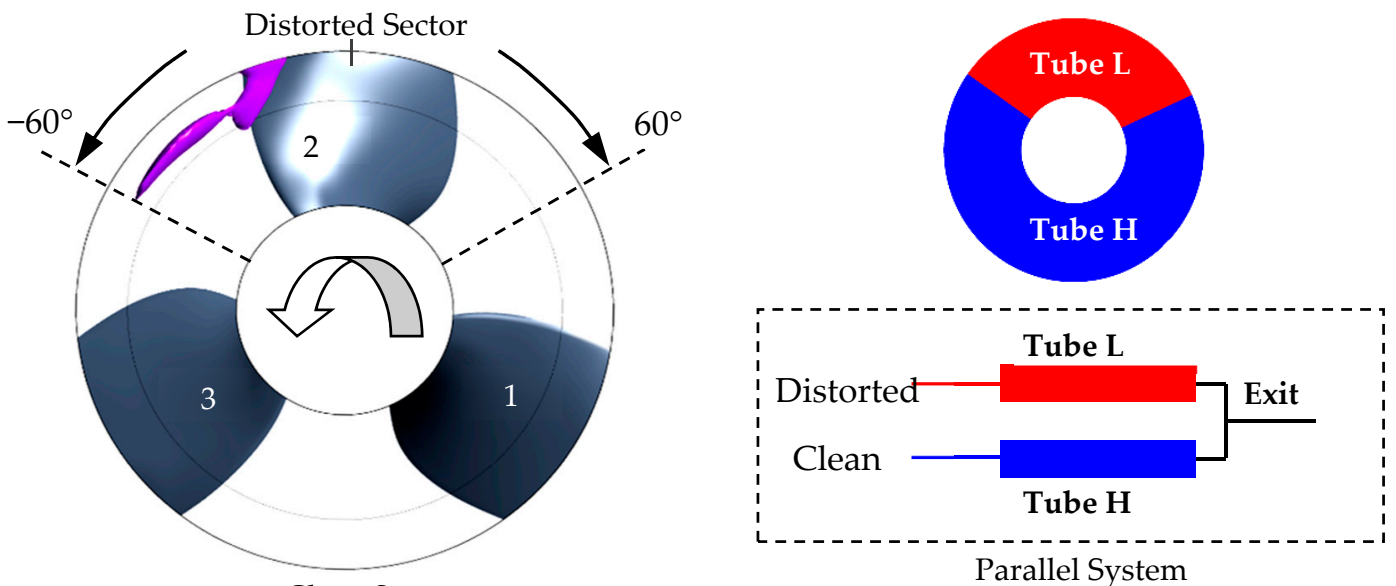

Figure 6. Parallel compressor model in waterjet pump with nonuniform inflow, the contour surface with $Q_{\mathrm{c}}=40,000 \mathrm{~s}^{-2}$ is chosen as the circumferential vortex, colored by purple.

In addition, the performance of waterjet pump under nonuniform inflow is equal to the resultant performance of tube $\mathrm{L}$ and tube $\mathrm{H}$ in the modified parallel pump system. In order to predict and estimate characteristics of tube $\mathrm{L}$ and tube $\mathrm{H}$, some assumptions 
should be put forward to improve the former parallel compressor theory: (1) the pump performance in each tube is identical to that obtained from uniform flow operation at the local value of flow rate, (2) each tube operates with different uniform inflow independently, (3) there is no circumferential flow migration between tube $\mathrm{L}$ and tube $\mathrm{H}$, (4) tube $\mathrm{L}$ and tube $\mathrm{H}$ has the same exit, where the total pressure or velocity is uniform.

With these assumptions, tube $\mathrm{L}$ and tube $\mathrm{H}$ have the same pump performance but with different inlet velocity (representing nonuniform inflow). In detail, the actual flow rate and head of waterjet pump under nonuniform inflow are theoretical calculated by using area weighted sum of flow rate and head of tube $\mathrm{L}$ and $\mathrm{H}$.

\section{Results}

\subsection{Application of Parallel Compressor Theory in Predicting Head of Waterjet Pump}

The flow rate and head of waterjet pump under nonuniform inflow was calculated by numerical simulation, the simulation results from the ship speed of $1 \mathrm{~m} / \mathrm{s}$ to $15 \mathrm{~m} / \mathrm{s}$ were subsequently listed in Table 2. According to modified parallel compressor theory, the flow rate and head of the parallel system were theoretical calculated by the area-weighted sum of tube $\mathrm{L}$ and $\mathrm{H}$, the theoretical calculation results were also listed in Table 2.

Table 2. Comparison between simulated and theoretical flow rate or head in different conditions.

\begin{tabular}{|c|c|c|c|c|c|c|}
\hline$v_{\mathrm{s}}(\mathrm{m} / \mathrm{s})$ & $Q_{\operatorname{sim}}\left(\mathrm{m}^{3} / \mathrm{h}\right)$ & $Q_{\mathrm{th}}\left(\mathrm{m}^{3} / \mathrm{h}\right)$ & Error (\%) & $H_{\text {sim }}(\mathrm{m}) *$ & $H_{\text {th }}(\mathrm{m})$ & Error (\%) \\
\hline 15 & 2956 & 2960 & 0.138 & 8.473 & 9.017 & 6.42 \\
\hline 14 & 2896 & 2900 & 0.150 & 8.718 & 9.181 & 5.31 \\
\hline 13 & 2844 & 2848 & 0.151 & 8.964 & 9.320 & 3.97 \\
\hline 12 & 2795 & 2800 & 0.157 & 9.238 & 9.450 & 2.29 \\
\hline 11 & 2752 & 2755 & 0.139 & 9.481 & 9.566 & 0.89 \\
\hline 10 & 2716 & 2720 & 0.140 & 9.726 & 9.720 & 0.07 \\
\hline 9 & 2680 & 2684 & 0.132 & 9.930 & 9.858 & 0.73 \\
\hline 8 & 2644 & 2647 & 0.123 & 10.125 & 9.954 & 1.70 \\
\hline 7 & 2608 & 2612 & 0.130 & 10.301 & 10.038 & 2.55 \\
\hline 6 & 2563 & 2566 & 0.126 & 10.363 & 10.199 & 1.59 \\
\hline 5 & 2525 & 2528 & 0.123 & 10.437 & 10.331 & 1.02 \\
\hline 4 & 2488 & 2492 & 0.143 & 10.538 & 10.444 & 0.9 \\
\hline 3 & 2447 & 2448 & 0.035 & 10.321 & 10.510 & 1.84 \\
\hline 2 & 2415 & 2419 & 0.133 & 10.542 & 10.500 & 0.39 \\
\hline 1 & 2394 & 2397 & 0.151 & 10.557 & 10.468 & 0.84 \\
\hline
\end{tabular}

Table 2 shows comparison of flow rate and pump head between numerical simulation and the modified parallel compressor theory. It is found that the theoretical value of flow rate is approximately equal to the simulated value, and relative errors are all less than $0.2 \%$ within the ship speed range. Meanwhile, the theoretical value of head is also in good agreement with the simulated value; the maximal relative error of head is $6.42 \%$ in the ship speed $15 \mathrm{~m} / \mathrm{s}$, and errors in other ship speed are nearly less than $4 \%$. It can be validated that the modified parallel compressor theory can accurately predict head of waterjet pump under nonuniform inflow.

Three reasons are summarized to explain the prediction deviation as follows: firstly, the resultant head is summed by area-weighted instead of mass-weighted. Besides, the circumferential flow actually exists and transfers energy between tube $\mathrm{L}$ and $\mathrm{H}$. Furthermore, the pump performance in each tube, especially at low flow rate, is incompletely identical to that obtained from uniform inflow. Although the prediction deviation results from assumptions of the modified parallel compressor theory, its value is in an acceptable range and has little impact on the variation trend of head with flow rate. Consequently, the modified parallel compressor theory is applicable in the external characteristics prediction for waterjet pump. 


\subsection{Application of Parallel Compressor Theory in Evaluating Stall Behavior of Waterjet Pump}

Figure 7 a depicts tube $\mathrm{L}$ and tube $\mathrm{H}$ having the same overall external characteristics (the grey line) obtained from uniform inflow but with different inlet velocity and flow rate (representing nonuniform inflow).

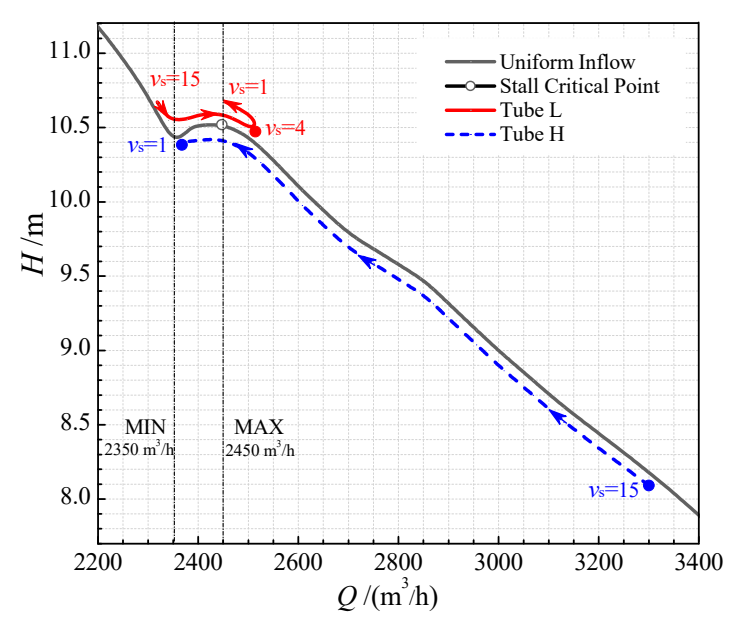

(a) Head curve

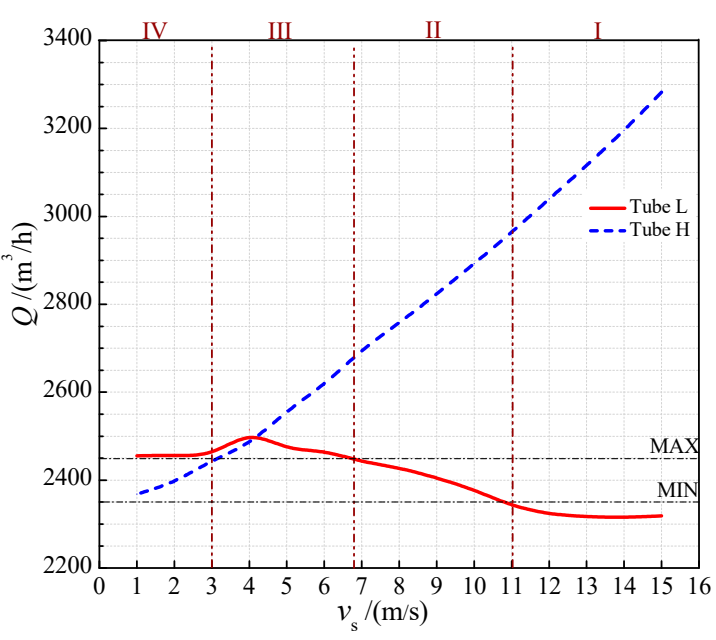

(b) Flow rate curve

Figure 7. Variations of head and flow rate of each tube in parallel waterjet pump system within the ship speed range from $1 \mathrm{~m} / \mathrm{s}$ to $15 \mathrm{~m} / \mathrm{s}$.

The grey line represents the flow rate-head curve of waterjet pump with uniform inflow, which was obtained by numerical simulation listed in Section 2.3. It is worth noting that pump head was also calculated by total pressure difference between impeller inlet and nozzle outlet instead. It must be emphasized that the grey line exhibits a hump and a valley respectively in Figure 7a. The hump corresponds to the maximal head point locating at the flow rate $2450 \mathrm{~m}^{3} / \mathrm{h}$. According to the approximate stall criterion raised by Emmons [22], the hump can be approximately regarded as the stall critical point of the pump. Namely, the pump or tube occurs stall when its operating flow rate is lower than $2450 \mathrm{~m}^{3} / \mathrm{h}$. In addition, the valley corresponds to the minimal head point locating at the flow rate $2350 \mathrm{~m}^{3} / \mathrm{h}$. It indicates that once the flow rate is lower than $2350 \mathrm{~m}^{3} / \mathrm{h}$, the pump or tube operates at deep stall condition, where a wide range of backflow exists.

The blue line describes the variations of head and flow rate of tube $\mathrm{H}$ with the reducing ship speed. It is noticed that the tube $\mathrm{H}$ keeps moving along the grey line from right to left, even climbs over the hump to the valley in Figure 7a; namely, the reducing ship speed induces lower flow rate of tube $\mathrm{H}$ in in Figure $7 \mathrm{~b}$, even resulting in stall occurrence of tube $\mathrm{H}$.

The red line illustrates the variations of head and flow rate of tube $L$ with the reducing ship speed. It is rather interesting note that tube L moves along the grey line from left to right, and then recircles around the hump in Figure 7a. That is to say, the flow rate of tube L firstly increases with the reducing ship speed, and then returns to reduce when the ship speed approaches $4 \mathrm{~m} / \mathrm{s}$. As demonstrated in Figure $7 \mathrm{~b}$, tube $\mathrm{L}$ obtains the largest flow rate in the ship speed $4 \mathrm{~m} / \mathrm{s}$. In particular, the ship speed of $4 \mathrm{~m} / \mathrm{s}$ is also a critical condition where the flow rate of tube $\mathrm{H}$ begins to be lower than that of tube $\mathrm{L}$. It is revealed that tube $\mathrm{H}$ probably occurs stall, even deep stall earlier than tube $\mathrm{L}$.

In order to identify when and which tube occurs stall more accurately, two isolines which values of flow rate are $2450 \mathrm{~m}^{3} / \mathrm{h}$ and $2350 \mathrm{~m}^{3} / \mathrm{h}$ respectively were added in Figure $7 \mathrm{~b}$. Thus, four ship speed zones were divided according to points of intersection of lines: isoline with value of flow rate of $2450 \mathrm{~m}^{3} / \mathrm{h}$ and $2350 \mathrm{~m}^{3} / \mathrm{h}$, flow rate curves of tube $\mathrm{L}$ and tube $\mathrm{H}$. Furthermore, the stall behavior of each tube at different ship speed zone will be analyzed systematically based on the following figures. 
Partial deep stall occurs in the ship speed range from $11 \mathrm{~m} / \mathrm{s}$ to $15 \mathrm{~m} / \mathrm{s}$ : tube $\mathrm{L}$ operates at deep stall condition, and tube $\mathrm{H}$ is beyond stall. As observed in the movement of blue point from Figure 8a to Figure 8c, the reducing ship velocity gives rise to a flow rate drop in tube $\mathrm{H}$, but tube $\mathrm{H}$ still operates at large flow rate which is far from the hump $\left(2450 \mathrm{~m}^{3} / \mathrm{h}\right)$ in this ship speed range. In contrast, the reducing ship velocity produces a flow rate increase in tube $\mathrm{L}$; the red point subsequently moves down toward the valley, but tube $\mathrm{L}$ operates at deep stall condition because its flow rate is lower than $2350 \mathrm{~m}^{3} / \mathrm{h}$. Consequently, tube $\mathrm{L}$ (deep stall) that accompanies tube $\mathrm{H}$ (beyond stall) contributes to a partial deep stall behavior in the parallel system, i.e., waterjet pump under nonuniform inflow.

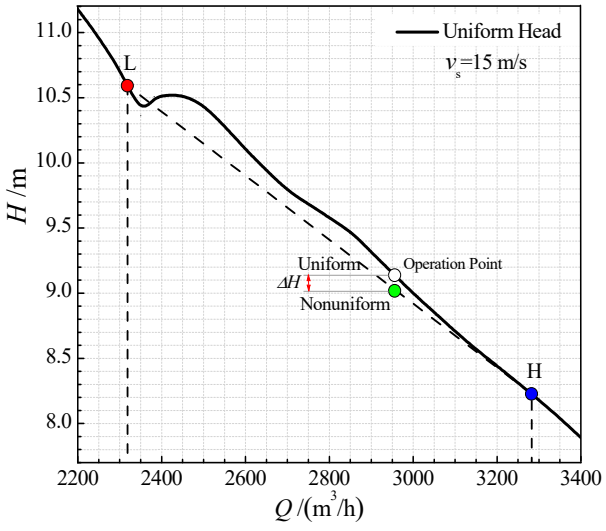

(a) $v_{\mathrm{s}}=15 \mathrm{~m} / \mathrm{s}$

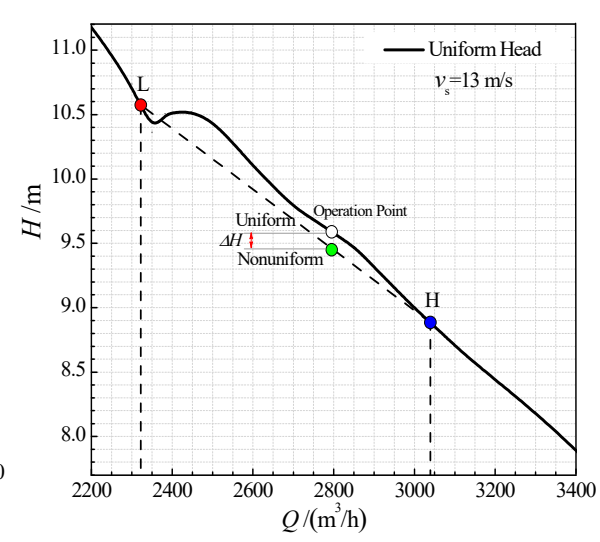

(b) $v_{\mathrm{s}}=12 \mathrm{~m} / \mathrm{s}$

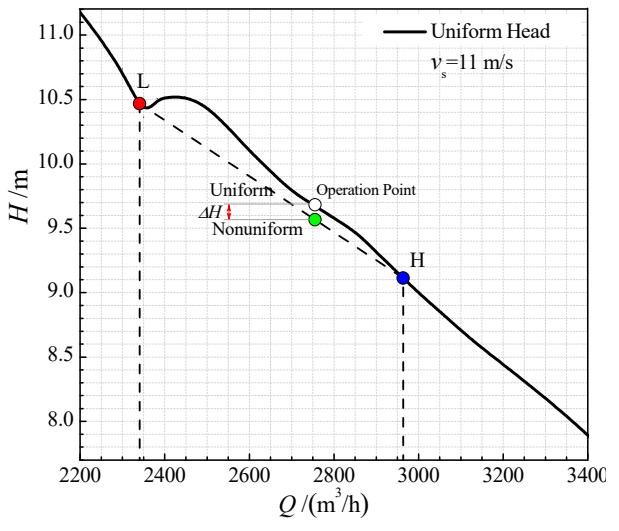

(c) $v_{\mathrm{s}}=11 \mathrm{~m} / \mathrm{s}$

Figure 8. Operating point comparison between tube $\mathrm{L}$ and $\mathrm{H}$, at partial deep stall condition.

Partial stall occurs in the ship speed range from $7 \mathrm{~m} / \mathrm{s}$ to $10 \mathrm{~m} / \mathrm{s}$ : tube $\mathrm{L}$ operates at stall condition, and tube $\mathrm{H}$ is beyond stall. As presented in the movement of blue point from Figure $9 \mathrm{a}-\mathrm{c}$, tube $\mathrm{H}$ keeps climbing the hump from the right side as the ship speed reduces, while the flow rate of tube $\mathrm{H}$ is still apparently larger than $2450 \mathrm{~m}^{3} / \mathrm{h}$ in this ship speed range. Meanwhile, tube L climbs the hump from the left side, and finally reaches the hump at ship speed $7 \mathrm{~m} / \mathrm{s}$; although the flow rate of tube $\mathrm{L}$ keeps increasing with the reducing ship speed, its value is still lower than $2450 \mathrm{~m}^{3} / \mathrm{h}$ which means that tube $\mathrm{L}$ always operates at stall condition. As a result, tube L (stall) combined with tube $\mathrm{H}$ (beyond stall) induces a partial stall behavior in the parallel system, i.e., waterjet pump under nonuniform inflow.

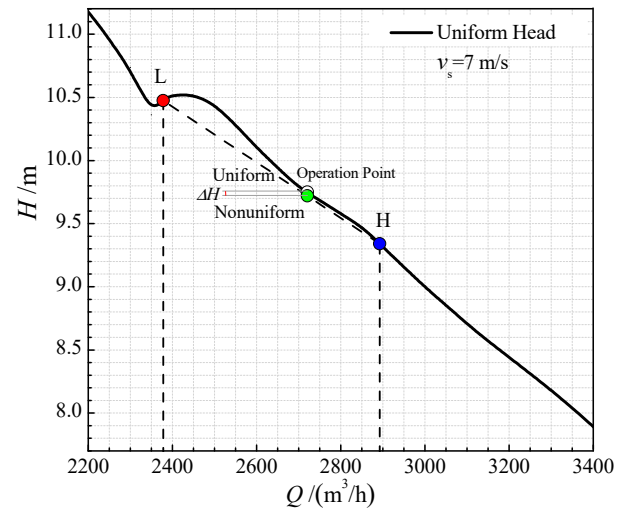

(a) $v_{\mathrm{s}}=10 \mathrm{~m} / \mathrm{s}$

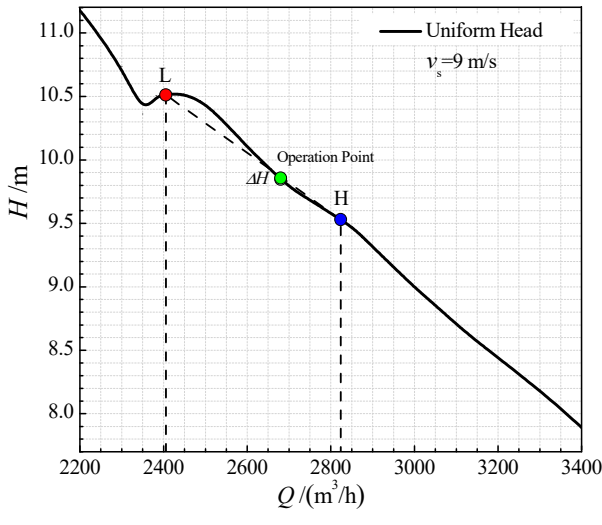

(b) $v_{\mathrm{s}}=9 \mathrm{~m} / \mathrm{s}$

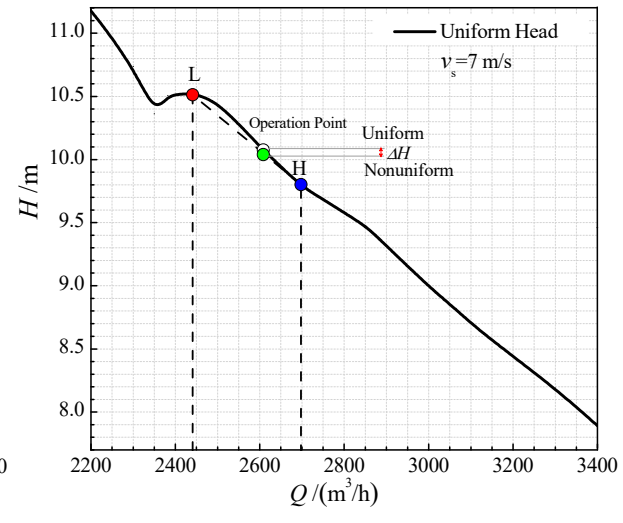

(c) $v_{\mathrm{s}}=7 \mathrm{~m} / \mathrm{s}$

Figure 9. Operating point comparison between tube $\mathrm{L}$ and $\mathrm{H}$, at partial stall condition. 
Pre-stall occurs in the ship speed range from $4 \mathrm{~m} / \mathrm{s}$ to $7 \mathrm{~m} / \mathrm{s}$ : both tube $\mathrm{L}$ and tube $\mathrm{H}$ operates at near-stall condition. As shown in the movement of blue point from Figure 10a to Figure 10c, tube $\mathrm{H}$ approaches close to the hump due to the reducing ship speed, with consequent a flow rate drop from $2700 \mathrm{~m}^{3} / \mathrm{h}$ to $2480 \mathrm{~m}^{3} / \mathrm{h}$; namely, tube H operates near the hump in this ship speed range. After climbing over the hump, tube L continues to move forward due to the reducing ship speed, with consequent an increase in flow rater even to the maximum at ship speed $4 \mathrm{~m} / \mathrm{s}$; it is noticed that the maximum value is about $2515 \mathrm{~m}^{3} / \mathrm{h}$, slight larger than $2450 \mathrm{~m}^{3} / \mathrm{h}$, so that tube $\mathrm{H}$ also operates near the hump. Hence, both tube $\mathrm{L}$ (near-stall) and tube $\mathrm{H}$ (near-stall) are responsible for a pre-stall behavior in the parallel system, i.e., waterjet pump under nonuniform inflow.

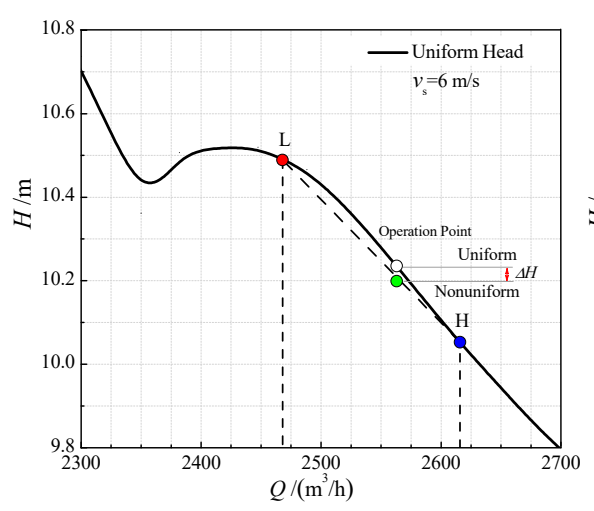

(a) $v_{\mathrm{s}}=6 \mathrm{~m} / \mathrm{s}$

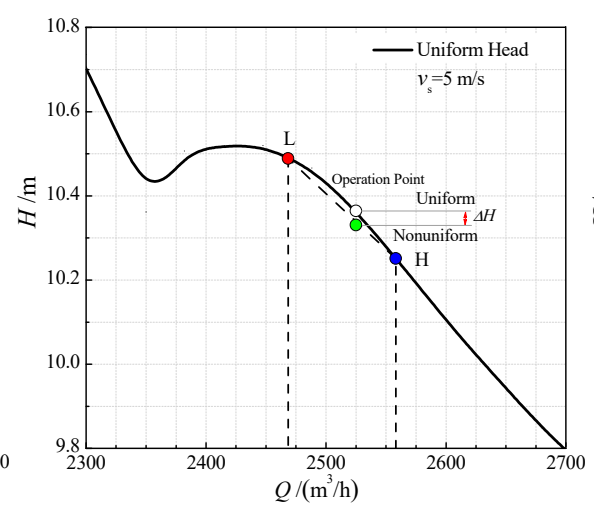

(b) $v_{\mathrm{s}}=5 \mathrm{~m} / \mathrm{s}$

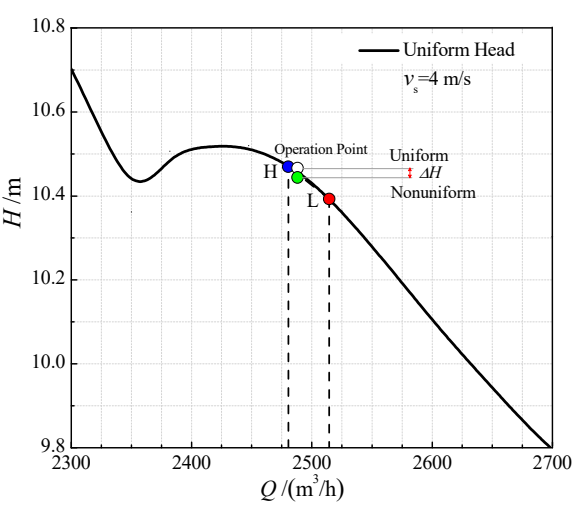

(c) $v_{\mathrm{s}}=4 \mathrm{~m} / \mathrm{s}$

Figure 10. Operating point comparison between tube $\mathrm{L}$ and $\mathrm{H}$, at pre-stall condition.

Full stall occurs in the ship speed from of $1 \mathrm{~m} / \mathrm{s}$ to $3 \mathrm{~m} / \mathrm{s}$ : tube $\mathrm{L}$ maintains stall inception and tube $\mathrm{H}$ operates at stall condition. As depicted in the movement of blue point from Figure 11a-c, tube $\mathrm{H}$ climbs up to the hump at ship speed $3 \mathrm{~m} / \mathrm{s}$; as the ship speed continues reducing, tube $\mathrm{H}$ gradually moves down toward the valley where the flow rate is lower than $2450 \mathrm{~m}^{3} / \mathrm{h}$; so, it is indicated that tube $\mathrm{H}$ operates at stall condition within this ship speed range. Additionally, tube $\mathrm{L}$ returns and rapidly climbs up to the hump again at ship speed $3 \mathrm{~m} / \mathrm{s}$, as evidenced by sharp flow rate drop; as the ship speed continues reducing, tube $\mathrm{L}$ fixes on the hump instead of moving down toward the valley as well as tube $\mathrm{H}$; so, it is indicated that tube $\mathrm{L}$ maintains the invariant stall condition owing to the unchanged flow rate. As a consequence, tube $\mathrm{L}$ (invariant stall) united with tube $\mathrm{H}$ (evolving stall) results in a full stall behavior in the parallel system, i.e., waterjet pump under nonuniform inflow.

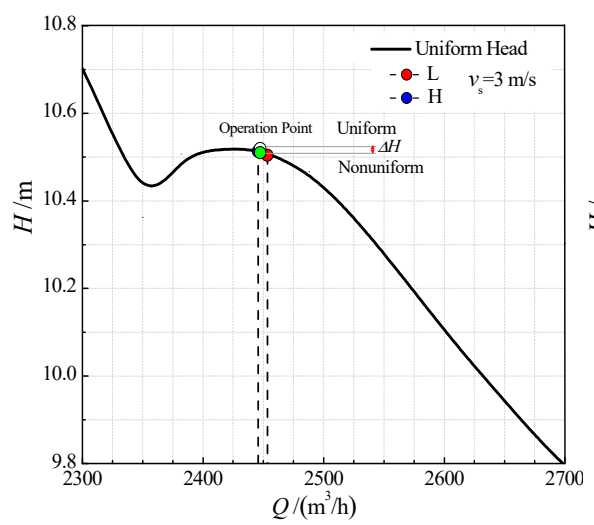

(a) $v_{\mathrm{s}}=3 \mathrm{~m} / \mathrm{s}$

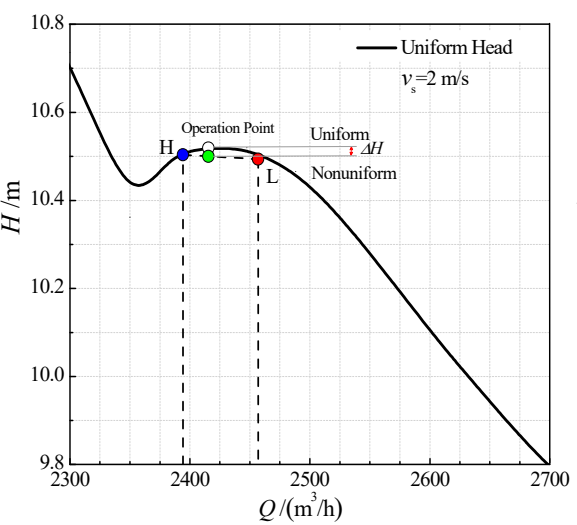

(b) $v_{\mathrm{s}}=2 \mathrm{~m} / \mathrm{s}$

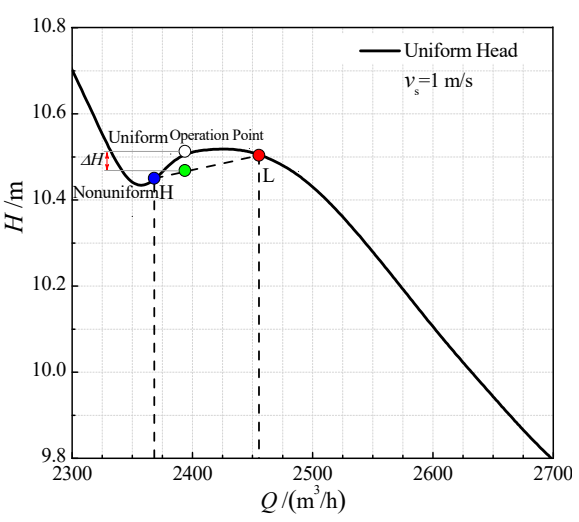

(c) $v_{\mathrm{s}}=1 \mathrm{~m} / \mathrm{s}$

Figure 11. Operating point comparison between tube $\mathrm{L}$ and $\mathrm{H}$, at full stall condition. 
According to the above analyzing of operation points of waterjet pump and its tubes under various ship speeds, stall behaviors under nonuniform inflow can be divided into partial deep stall, partial stall, stall inception and full stall. Namely, nonuniform inflow gives rise to partial stall in the tube, resulting in flow instability of the whole parallel pump system although its total flow rate under uniform inflow is far away from instability limiting line.

\section{Discussion}

\section{Correlation between Multi-Segment Head Curve and Stall Behavior under Nonuniform Inflow}

Operating points of tube $\mathrm{L}$ and $\mathrm{H}$ also have a dominant effect on variations of head curve at four different stall conditions, and consequently can exhibit a multi-segment head curve instead of the traditional parabolic curve in Figure 12. In order to explore its generation mechanism, the following analysis is focused on the change rule of each segment head curve and its corresponding stall behavior in the established parallel pump system.

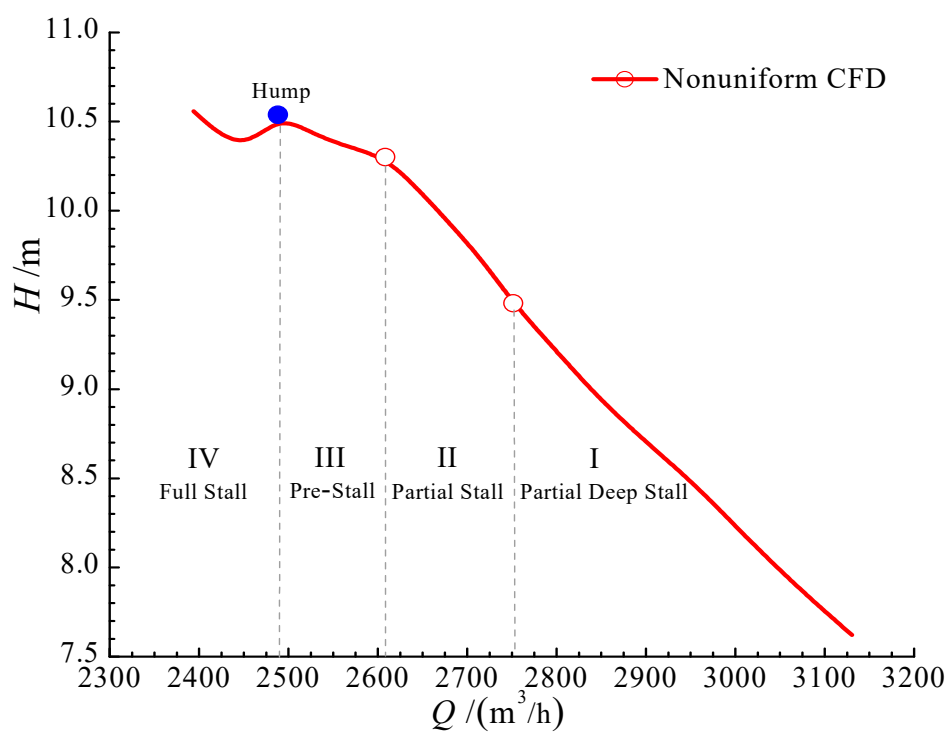

Figure 12. Multi-segment head curve of waterjet pump under nonuniform inflow.

I-segment exhibits a slowly increasing head curve with the reducing flow rate, corresponding to partial deep stall. From the view of the established parallel pump system, tube $\mathrm{H}$ operates far from hump and its head increases with the reducing flow rate, as shown in Figure 8. In contrast, lower ship speed produces larger flow grate in tube L, with consequent a drop in pump head even to the minimum; this head drop in tube $L$ then offsets the increment of head in tube H. Consequently, the growth of head slows down in the parallel system (i.e., waterjet pump under nonuniform inflow).

II-segment exhibits an accelerated increasing head curve with the reducing flow rate, corresponding to partial stall. From the view of the established parallel pump system, tube $\mathrm{H}$ maintains climbing along head curve under uniform inflow to obtain higher head and lower flow rate, as plotted in Figure 9. Meanwhile, tube L climbs along the same head curve on the opposite direction, so that the head increases from the valley to the peak as the flow rate of system reduces; the increasing head in tube L superposes with the increasing head in tube $\mathrm{H}$. As a result, the growth of head accelerates in the parallel system (i.e., waterjet pump under nonuniform inflow).

III-segment exhibits a new slowly increasing head curve with the reducing flow rate corresponding to pre-stall. From the view of the established parallel pump system, tube $\mathrm{H}$ approaches close to the hump due to the reducing flow rate, with consequent an increase in head of 5\%, as presented in Figure 10. After climbing over the hump, the head of tube L 
stops increasing and even turns back to reduce; this head drop in tube L also offsets the increment of head in tube $\mathrm{H}$. Hence, the growth of head slows down again in the parallel system (i.e., waterjet pump under nonuniform inflow).

IV-segment exhibits a saddle-shaped head curve with the reducing flow rate, corresponding to full stall. From the view of the established parallel pump system, tube $\mathrm{H}$ climbs over the hump and then occurs stall, its head thus reduces as the flow rate of system decreases, as illustrated in Figure 11. Additionally, the fixed tube L maintains the invariant stall condition and pump head; this unchanged head in tube L has a slight effect on the variant of system head curve. As a consequence, the head curve in the parallel system (i.e., waterjet pump under nonuniform inflow) is consistent with a saddle-shaped curve of tube $\mathrm{H}$.

In conclusion, nonuniform inflow gives rise to partial stall and flow instability of waterjet pump, resulting in a multi-segment head curve representing weaken performances.

\section{Conclusions}

Based on the modified parallel compressor theory, a parallel pump system composed of two circumferential tubes, i.e., tube L (distorted) and tube $\mathrm{H}$ (clean) was established and then utilized to predict waterjet pump performances under the nonuniform inflow. Besides, the distorted waterjet pump performances were also simulated using the RNG $k-\varepsilon$ model and multi-block grids. On the basis of the performance comparison, the applicability of PCT was validated and the correlation between the multi-segment head curve and stall behavior was discussed. The main conclusions are summarized as below:

The modified parallel compressor theory is applicable to accurately predicting external characteristics of waterjet pump under the nonuniform inflow. This is due to the fact that the area-weighted sum flow rate and pump head based on the modified parallel compressor theory are highly consistent with the simulated results: the relative errors of flow rate values in different ship speeds are all less than $0.2 \%$; in addition, the relative errors of head values are almost less than $4 \%$.

The modified parallel compressor theory is applicable to evaluating internal flow instability of waterjet pump under nonuniform inflow. According to when and which tube occurs stall, four different stall behavior of the waterjet pump has been determined: (1) Partial deep stall ranges from $11 \mathrm{~m} / \mathrm{s}$ to $15 \mathrm{~m} / \mathrm{s}$ : tube L occurs deep stall, and tube $\mathrm{H}$ is beyond stall; (2) Partial stall ranges from $7 \mathrm{~m} / \mathrm{s}$ to $10 \mathrm{~m} / \mathrm{s}$ : tube $\mathrm{L}$ occurs stall, and tube $\mathrm{H}$ is beyond stall; (3) Pre-stall ranges from $4 \mathrm{~m} / \mathrm{s}$ to $7 \mathrm{~m} / \mathrm{s}$ : both tube $\mathrm{L}$ and tube $\mathrm{H}$ operates at near-stall condition; (4) Full stall ranges from $1 \mathrm{~m} / \mathrm{s}$ to $3 \mathrm{~m} / \mathrm{s}$ : tube L maintains stall inception, and tube $\mathrm{H}$ occurs stall condition.

Observations elucidate the internal correlation between the multi-segment head curve and stall behavior. I-segment head curve increases slowly during partial deep stall range, because the head drop in tube L offsets the head increment in tube H; II-segment head accelerated increases during partial stall range, as evidenced by the increment addition in head of tube $\mathrm{L}$ and tube $\mathrm{H}$; III-segment head curve slows down during pre-stall range, due to the fact that a new head drop in tube L offsets the head increment in tube H; IVsegment is consistent with a saddle-shaped head curve of tube $\mathrm{H}$, since tube L maintains its operation and head over full stall range.

Finally, nonuniform inflow induces partial stall and flow instability of the waterjet pump, resulting in weaken head in the actual application. We hope that the achieved results could provide a sufficient understanding of the role of the nonuniform inflow in external characteristic and internal flow instability of waterjet pump.

Author Contributions: Conceptualization, P.C.; methodology, P.C.; validation, P.C., software, R.Z.; writing — original draft preparation, R.Z.; writing—review and editing, R.Z. and P.C. All authors have read and agreed to the published version of the manuscript.

Funding: This research was funded by Natural Science Foundation of Jiangsu Province: BK 20190847, China Postdoctoral Science Foundation: 2019M661744, National Key R\&D Program of China: 
2018YFB0606101, National Natural Science Foundation of China: 51879120, Priority Academic Program Development of Jiangsu Higher Education Institutions (PAPD).

Institutional Review Board Statement: Not applicable.

Informed Consent Statement: Not applicable.

Data Availability Statement: Data sharing not applicable.

Conflicts of Interest: On behalf of all authors, the corresponding author states that there are no conflict of interest.

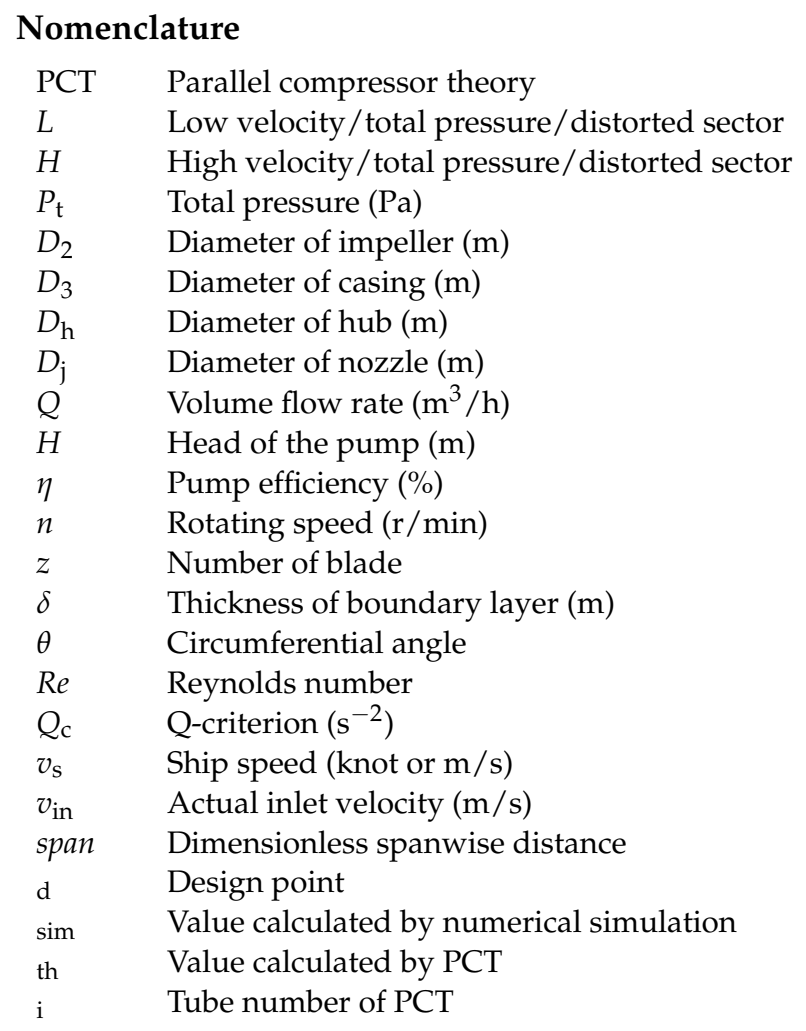

\section{References}

1. Bulten, N.W.H. Numerical Analysis of a Waterjet Propulsion System. Ph.D. Thesis, Eindhoven University of Technology, Eindhoven, The Netherlands, 2006.

2. Cao, P.Y.; Wang, Y.; Kang, C.; Li, G.D.; Zhang, X. Investigation of the role of non-uniform suction flow in the performance of water-jet pump. Ocean. Eng. 2017, 140, 258-269. [CrossRef]

3. Van Esch, B.P.M. Performance and radial loading of a mixed-flow pump under non-uniform suction flow. J. Fluids Eng. Trans. ASME 2009, 131, 051101. [CrossRef]

4. Duerr, P.; Von Ellenrieder, K.D. Scaling and numerical analysis of nonuniform waterjet pump inflows. IEEE J. Oceanic. Eng. 2015, 40, 701-709. [CrossRef]

5. Luo, X.W.; Ye, W.; Huang, R.F.; Wang, Y.; Du, T.; Huang, C. Numerical investigations of the energy performance and pressure fluctuations for a waterjet pump in a non-uniform inflow. Renew. Energy 2020, 153, 1042-1052. [CrossRef]

6. Cao, P.Y.; Wang, Y.; Zhang, X.; Li, G.D.; Yin, G. Concentrated separation vortex induced by non-uniform suction flow and its role in performance breakdown of a water-jet pump. Adv. Mech. Eng. 2017, 9. [CrossRef]

7. Johnsen, I.A.; Bullock, R.O. Aerodynamic Design of Axial-Flow Compressors: NASA SP-36; National Aeronautics and Space Administration: Washington, DC, USA, 1965.

8. Smith, S.L. One-Dimensional Mean Line Code Technique to Calculate Stage-by-Stage Compressor Characteristics. Master's Thesis, University of Tennessee, Knoxville, TN, USA, 1999.

9. Cumsty, N.A. Compressor Aerodynamics, 1st ed.; Longman Scientific \& Technical: London, UK, 1989.

10. Greitzer, E.M. Surge and rotating stall in axial flow compressors-part I: Theoretical compression system model. J. Eng. Power 1976, 98, 190-198. [CrossRef]

11. Korn, J.A. Estimated effect of circumferential distortion on axial compressors using parallel compressor theory and dynamic stall delay. In Proceedings of the 12th Aerospace Sciences Meeting and Exhibit (AIAA), Washington, DC, USA, 9-12 January 1974. 
12. Shahrokhi, K.; DAVIS, M.W. Application of a modified dynamic compression system model to a low aspect ratio fan: Effects of inlet distortion. In Proceedings of the 33rd Aerospace Sciences Meeting and Exhibit (AIAA), Reno, NV, USA, 5-8 August 1995.

13. Pokhrel, M.; Gladin, J.; Garcia, E.; Mavris, D.N. A methodology for quantifying distortion impacts using a modified parallel compressor theory. In Proceedings of the ASME Turbo Expo: Turbomachinery Technical Conference and Exposition, Oslo, Norway, 11-15 June 2018.

14. O'Brien, W. A three-dimensional turbine engine analysis compressor code (TEACC) for steady-state inlet distortion. J. Turbomach. 1998, 120, 423-435.

15. Davis, M.W.; Kidman, D.S. Prediction and analysis of inlet pressure and temperature distortion on engine operability from an accent T-38 flight test program. In Proceedings of the Turbo Expo: Power for Land, Sea, and Air, Glasgow, UK, 14-18 June 2010

16. Floyd, R.S.; DAVIS, M.W. Validation of a modified parallel compressor model for prediction of the effects of inlet swirl on compressor performance and operability. In Proceedings of the ASME Turbo Expo: Turbomachinery Technical Conference and Exposition, Montreal, QC, Canada, 15-19 June 2015.

17. SAE S-16 Committee. Inlet Total-Pressure-Distortion Considerations for Gas-Turbine Engines; Society of Automatical Engineering International: Warrendale, DC, USA, 2013.

18. Zhao, X.; Liu, T.; Huang, B.; Wang, G.Y. Combined experimental and numerical analysis of cavitating flow characteristics in an axial flow waterjet pump. Ocean. Eng. 2020, 209, 107450. [CrossRef]

19. Guo, Q.; Huang, X.N.; Qiu, B. Numerical investigation of the blade tip leakage vortex cavitation in a waterjet pump. Ocean. Eng. 2020, 187, 106170. [CrossRef]

20. Huang, R.; Dai, Y.; Luo, X.W.; Wang, Y.; Huang, C. Multi-objective optimization of the flush-type intake duct for a waterjet propulsion system. Ocean. Eng. 2019, 187, 106172. [CrossRef]

21. Stel, H.; Amaral, G.D.L.; Negrao, C.O.R.; Chiva, S.; Estevam, V.; Morales, R.E.M. Numerical analysis of the fluid flow in the first stage of a two-stage centrifugal pump with a vanned diffuser. J. Fluids Eng. Trans. 2013, 135, 235-244.

22. Emmons, H.W.; Pearson, C.E.; Grant, H.P. Compressor surge and stall propagation. Z. Angew. Math. Phys. ZAMP 1955, 77, 455-469. 